\title{
Relativistic Effects and the Chemistry of Gold*
}

\author{
Neil Bartlett \\ Department of Chemistry, and Chemical Sciences Division, LBNL, University of California, Berkeley, CA 94720
}

\begin{abstract}
In atoms of high nuclear charge $(\mathrm{Z})$, as a consequence of a relativistic effect, the $s$ electrons of an atom become more bound and their orbitals smaller than if this effect were absent. Simultaneously, the $d$ (and $f$ ) electrons are less bound because of this effect, which scales roughly as $Z^{2}$. Gold exhibits a large relativistic effect. This accounts for gold being more resistant to oxidation than silver. It also accounts for higher oxidation states being more accessible in gold than in silver. These effects are illustrated by some fluorine chemistry of gold and silver.
\end{abstract}

Differences in the chemistry of gold compared with that of silver, particularly the initial resistance of gold to oxidation, and its greater extent of oxidation once oxidized, can be attributed largely to the impact of a relativistic effect. The importance of this for gold chemistry was noted by Pitzer (1) and Pyykkö and Desclaux (2) nearly twenty years ago. More recently Kaltsoyannis (3) has summarized the impact of the effect for inorganic and organometallic chemistry.

As atomic nuclear charge $(\mathrm{Z})$ increases, electrons that penetrate to the nucleus (the $\boldsymbol{s}$ electrons) increase their average velocity and as a consequence of relativity, their mass. This relativistic effect causes the $\boldsymbol{s}$ electrons (and to a lesser extent, the $\mathbf{p}$ electrons) to be in smaller orbitals than if this effect were absent. Therefore, in the heavier elements, the $\boldsymbol{s}$ electrons are more strongly bound and shield the nuclear charge from the other electrons (especially $\mathbf{d}$ and $\mathbf{f}$ ) more effectively than if the relativistic effects were absent. The $\mathbf{d}$ and $\mathbf{f}$ electrons are therefore less bound and occupy larger orbitals when relativistic effects are large. These effects scale roughly with $Z^{2}$ and become important for elements heavier than the lanthanides (4). For the elements gold to bismuth the impact on energies is comparable with chemical bond energies (1). Indeed, gold, because it is also at the end of the $\mathbf{5 d}$ orbital

\footnotetext{
* Dedicated to Kenneth Sanborn Pitzer, my late teacher, colleague and friend, who first made me aware of this relativistic effect
}

filling, (third transition series contraction effect) following on the if filling (lanthanide contraction) exhibits maximum impact of this relativistic effect (2-4).

As a consequence of the lanthanide contraction and the relativistic effect we expect that the effective size of the isolated gold (gaseous) atom will be comparable with that of silver, although presently neither atom size is known. What is known, however, is that the relativistic effect in gold enhances the binding of the $s$ electrons relative to those of silver. This accounts for the smaller size established by Schmidbaur and his coworkers [5] for $\mathrm{Au}(\mathrm{I})$ versus $\operatorname{Ag}(1)$; the high electron affinity of gold relative to silver (see Table 1), and for the existence of the aurides (eg $\left.\mathrm{Cs}^{+} \mathrm{Au}^{-}\right)$which are non-metallic semiconductors (6). It is also why the first ionization potential of gold (removing the $\boldsymbol{s}$ electron from the $\mathbf{5 d}^{10} \mathbf{6} \boldsymbol{s}$ configuration) is so much higher than that of silver (see Table). The tighter binding of the $\boldsymbol{s}$ electrons of gold also accounts for the greater cohesion energy of gold metal since the valence $\boldsymbol{s}$ electron contributes most to that bonding. The enthalpies of atomization (see Table) reflect this. The tighter binding of the valence $\boldsymbol{s}$ electron of gold also contributes to the higher melting point, and smaller atom to atom close contact in the metal. The raising of the Au $\mathbf{5 d}$ electron energies and the lowering of the valence $\mathbf{6 s}$ also accounts for the yellow color of gold (absorption beginning at $\sim 2.38 \mathrm{eV}$ ) associated with transitions from the $5 \mathbf{d}$ band to the Fermi level (largely $\mathbf{6 s}$ in character) (11). 
Table 1 Comparing Gold with Silver

\begin{tabular}{|c|c|c|c|c|}
\hline & & Au & $\mathbf{A g}$ & Refs \\
\hline Ionization potentials $(\mathrm{eV})$ & $\begin{array}{l}\text { Ist: } \\
\text { 2nd: }\end{array}$ & $\begin{array}{l}9.225 \\
20.5\end{array}$ & $\begin{array}{l}7.576 \\
21.49\end{array}$ & 7 \\
\hline Electron affinity $(\mathrm{eV})$ & & 2.039 & 1.202 & 8 \\
\hline $\begin{array}{l}\left.\text { Heats of atomization (kjoules } \mathrm{mol}^{-1}\right) \\
\text { Melting point }\left({ }^{\circ} \mathrm{C}\right)\end{array}$ & & $\begin{array}{c}368 \\
1063\end{array}$ & $\begin{array}{l}285 \\
961\end{array}$ & 9 \\
\hline A-A distance in f.c.c. cells $(\AA), 25^{\circ} \mathrm{C}$ : & & 2.8840 & 2.8894 & 10 \\
\hline
\end{tabular}

The related absorption in silver ( $\mathbf{4} \mathbf{d}$ band to the Fermi level of $\sim \mathbf{5 s}$ character) is in the ultraviolet, at $-3.7 \mathrm{eV}$.

Detailed appraisals of the impact of the relativistic effect upon the size of $A u(I)$ versus $A g(I)$ have already been given by Schmidbaur and his coworkers (5) and have been summarized in this journal (12). In this paper, emphasis is given to the impact of the effect on the attainment of higher oxidation states in gold, compared with silver.

As we have seen, the consequences of the relativistic effect have prime impact in causing metallic gold to be more resistant to oxidation than silver. If a sufficiently potent oxidizer is available however, gold can be oxidized to a higher oxidation state than silver, and again this is a consequence of the relativistic effect. Fluorine usually excites the highest and the greatest range of oxidation states for an element. This is so for gold and silver. It is in the fluorine chemistry of these elements therefore that the large relativistic effect in the chemistry of gold is best seen.

\section{SOME FLUORINE CHEMISTRY OF GOLD AND SILVER}

\section{Chemistry in liquid anbydrous hydrogen fluoride}

When metallic gold is exposed to elemental fluorine $\left(\mathrm{F}_{2}\right)$ at room temperature in the presence of the ionizing solvent liquid anhydrous hydrogen fluoride $(\mathrm{aHF})$ containing an alkali fluoride, the metal is quickly dissolved to give the alkali salt of the anion $\mathrm{AuF}_{4}^{-}{ }^{-}(13)$ :

$$
\mathrm{Au}(\mathrm{s})+\mathrm{F}_{(\text {solv })}^{-}+3 /{ }_{2} \mathrm{~F}_{2(\mathrm{~g})} \stackrel{\mathrm{aHF}_{4},-20^{\circ} \mathrm{C}}{\longrightarrow} \mathrm{AuF}_{4}^{-} \text {(solv) }
$$

Under similar conditions silver is oxidized only to the +2 oxidation state, the ultimate product being $\mathrm{AgF}_{2}$, which is not soluble in aHF. If however the $F_{2}$ is photo- dissociated to atoms (sunlight will do) the $\mathrm{AgF}_{2}$ is further oxidized and dissolves in the aHF made basic with alkali fluoride (14):

$$
\mathrm{AgF}_{2(\mathrm{~s})}+\mathrm{F}_{(\text {solv })}^{-}+\mathrm{F}_{(\text {solv })}^{\bullet} \stackrel{\mathrm{aHF}, \sim 20^{\circ} \mathrm{C}}{\longrightarrow} \mathrm{AgF}_{4}^{-} \text {(solv) }
$$

Under such conditions (of photo-dissociated $\mathrm{F}_{2}$ ) $\mathrm{AuF}_{4}$ is oxidized further, to $\mathrm{AuF}_{6}^{-}(15)$ :

$$
\mathrm{AuF}_{4}^{-} \text {(solv) }+2 \mathrm{~F}^{\circ}{ }_{\text {(solv) }} \stackrel{\mathrm{aHF},-20^{\circ} \mathrm{C}}{\longrightarrow} \mathrm{AuF}_{6}^{-} \text {(solv) }
$$

These reactions clearly demonstrate how much more easily the $\mathbf{5 d}$ electrons of gold can be involved in bonding than can the $\mathbf{4 d}$ electrons of silver. The stronger binding of the silver $\mathbf{4 d}$ electrons is already indicated (see Table) by the second ionization potential, which is about $1 \mathrm{eV}$ higher than that of Au. Not only are the $\mathrm{Au}$ 5d electrons less firmly bound than the $\mathrm{Ag}$ $\mathbf{4 d}$, but $\mathbf{5 d}$ orbitals are also much larger than the $\mathbf{4 d}$ of $\mathrm{Ag}$. This is clearly shown by related $\mathrm{Au}(\mathrm{III})$ and $\mathrm{Ag}(\mathrm{III})$ structures.

\section{Comparison of the structures of $A u(I I I)$ and $\mathrm{Ag}($ III $)$}

The structures (16) of $\mathrm{AuF}_{3}$ and $\mathrm{AgF}_{3}$ are represented in Figure 1. In the approximately square arrangement of four $\mathrm{F}$ ligands about each $\mathrm{A}(\mathrm{A}=\mathrm{Au}$ or $\mathrm{Ag})$ atom (in the local xy plane) the $\mathrm{Au}-\mathrm{F}$ interatomic distances are slightly larger than those of Ag-F, but not significantly so. Simpler comparison of square coordinate $\mathrm{A}(\mathrm{III})$ is made, in $\left[\mathrm{AF}_{4}\right]^{-}$salts, where all four $\mathrm{A}-\mathrm{F}$ distances are equivalent. For $\mathrm{KAgF}_{4}(17), \mathrm{Ag}-\mathrm{F}=1.899(3) \AA$ and for $\mathrm{RbAuF}_{4}(18), \mathrm{Au}-\mathrm{F}=1.915(3) \AA$. The bonding in the square coordinate $\mathrm{AF}_{4}^{-}$(and related units in $\mathrm{AF}_{3}$ ) uses four A oribitals and four ligand orbitals. The A orbitals are the valence $\mathbf{s}$, two $\mathbf{p}$ orbitals, and a $\mathbf{d}$ orbital. As we have seen, the valence $\boldsymbol{s}$ orbital of Au should provide better binding energy than that of silver, but this is largely offset by the poorer binding provided by the $\mathbf{5 d}$ orbital of Au compared with the $\mathbf{4 d}$ of $\mathrm{Ag}$. The impact of the relativistic effect on $\mathbf{p}$ orbitals is complex $(1,2,4)$ and in such cases as $\left[\mathrm{AF}_{4}\right]^{-}$is probably slight. The overall relativistic impact on the binding in square- 


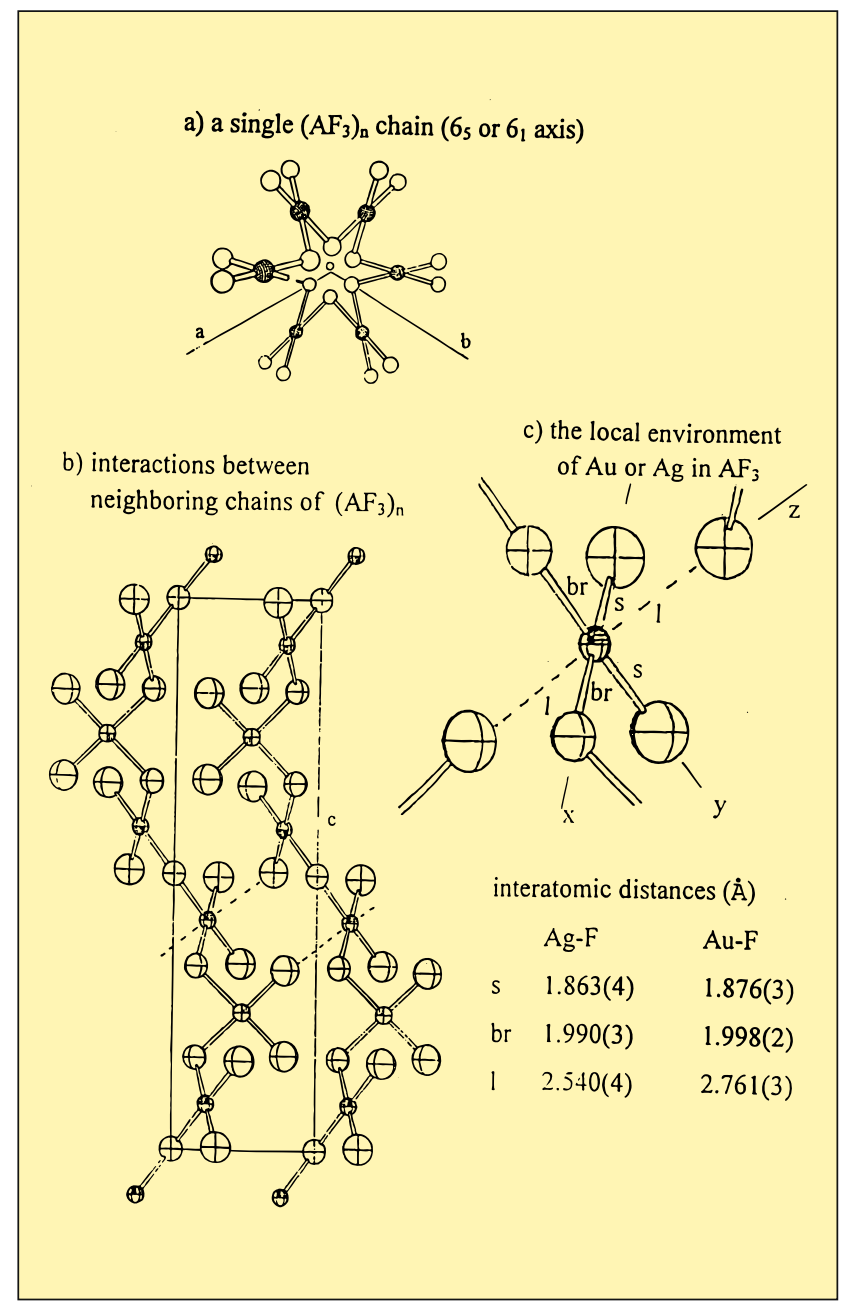

Figure 1 Comparison of the fluorine ligand arrangement about the gold and silver atoms in the structurally related trifluorides $\mathrm{AuF}_{3}$ and $\mathrm{AgF}_{3}$ (reference 16)

coordinate $\mathrm{A}(\mathrm{III})$ is therefore small. The big difference, however, in both the $\mathrm{AF}_{3}$ and $\left[\mathrm{AF}_{4}\right]^{-}$salt structures, lies in the size of the 'non-bonding' valence $\mathbf{d}$ orbitals of the A(III).

As may be seen from the Figure, the interatomic distances of $\mathrm{AF}_{3}$, approximately normal to the closebonded $\mathrm{AF}_{4}$ groups, are long in each case, but the Au.. $\mathrm{F}$ distance is $0.22 \AA$ longer than Ag...F. This can be attributed to the larger size of the gold 'non-bonding' valence $\mathbf{d}$ electron pair that occupies the local z-axis region. This greater size of the 'non-bonding' valence $\mathbf{d}$ electron orbitals of gold, relative to those of silver, is of course consistent with the weaker binding of $\mathrm{Au} \mathbf{5 d}$ electrons versus the $\mathrm{Ag} \mathbf{4 d}$. It is also revealed in the formula unit volumes of the $\mathrm{AF}_{3}$ and the $\left[\mathrm{AF}_{4}\right]^{-}$salts. Each gold compound is $-5 \AA^{3}$ larger, per formula unit, than its silver counterpart. This is in harmony with the observed chemistry.

\section{Contrasting the instability of $A u F_{2}$ with the stability of $\mathrm{AgF}_{2}$}

The relativistic effect also accounts for the observed instability (19) of $\mathrm{AuF}_{2}$ with respect to metallic gold and $\mathrm{Au}(\mathrm{III})$ products. Although the large and highly stable anion $\mathrm{SbF}_{6}{ }^{-}$does provide (19) for the preparation of the simple-paramagnet $\mathrm{Au}^{2+}\left[\mathrm{SbF}_{6}\right]_{2}^{-}$, the interaction of this with excess alkali fluoride in aHF leads to complete disproportionation of the $\mathrm{Au}(\mathrm{II})$ :

$$
8 \mathrm{~F}^{-}{ }_{(\text {solv })}+3 \mathrm{Au}^{2+}{ }_{(\text {solv })} \stackrel{\mathrm{aHF},-20^{\circ} \mathrm{C}}{\longrightarrow} \mathrm{Au}_{(\mathrm{s})}+2 \mathrm{AuF}_{4}^{-} \text {(solv) }
$$

Similar treatment of $\mathrm{Ag}^{2+}\left[\mathrm{SbF}_{6}\right]_{2}{ }^{-}$gives $\mathrm{AgF}_{2}$ and the alkali salt of $\mathrm{SbF}_{6}^{-}$. This facile disproportionation of $\mathrm{Au}(\mathrm{II})$ to $\mathrm{Au}(0)$ and $\mathrm{Au}(\mathrm{III})$ and the absence of such disproportionation for $\mathrm{Ag}(\mathrm{II})$, expresses the tighter binding in $A(0)$ provided by the $\mathbf{6 s}$ electron of $\mathrm{Au}$, and the easier engagement of the $\mathbf{5 d}$ electrons of $\mathrm{Au}$ (compared with the $\mathbf{4} \mathbf{d}$ of $\mathrm{Ag}$ ) in the formation of A(III).

\section{Concerning $\mathrm{AuF}_{6}^{-}, \mathrm{AgF}_{6}^{-}$and the possibility of preparing $A u_{6}$}

As the ready oxidation of $\mathrm{AuF}_{4}^{-}$to $\mathrm{AuF}_{6}^{-}$\{equations (3)\} illustrates, the 'non-bonding' $\mathrm{z}$ axis $\mathbf{d}$ orbital electron-pair of the $\mathrm{Au}(\mathrm{III})$ is easily engaged in bonding by two $\mathrm{F}$ atoms, which add. In contrast $\mathrm{AgF}_{6}^{-}$ solution species have not been similarly preparable from $\mathrm{AgF}_{4}^{-}$, even using the most potent of known oxidative fluorinators, $\mathrm{KrF}_{2}(20)$.

As we have seen it is relatively easy, with fluorine, to obtain $\mathrm{Au}(\mathrm{V})$ but can higher oxidation states than this also be realized? Of particular interest is the molecule $\mathrm{AuF}_{6}$. The hexafluorides of the third transition series are known from tungsten through to platinum and the electron affinity of each of these gaseous molecules is greater by $-1 \mathrm{eV}$ for each unit increase in atomic number of the metal (21). The electron affinity of $\mathrm{PtF}_{6}$ is nearly $8 \mathrm{eV}$, and $\mathrm{E}\left(\mathrm{AuF}_{6}\right)$ is expected (22) to be $1 \mathrm{eV}$ higher. Miyoshi and Sakai (23) have calculated $\mathrm{E}\left(\mathrm{AuF}_{6}\right)$ to be $9.56 \mathrm{eV}$, in agreement with that rough estimate. This means, of course, that the $\mathrm{AuF}_{6}^{-}$is difficult to oxidize. Cationic $\mathrm{Ag}(\mathrm{III})$ and $\mathrm{Ni}(\mathrm{IV})$, which are potent oxidizers in liquid $\mathrm{HF}$, are able to oxidize $\mathrm{PtF}_{6}{ }^{-}$to $\mathrm{PtF}_{6}$ but not $\mathrm{AuF}_{6}^{-}$to $\mathrm{AuF}_{6}$ (24). It is possible that the remaining valence $\mathbf{d}$ orbital electrons of gold in $\mathrm{AuF}_{6}{ }^{-}$(which constitute a ligand-field stabilized $\mathrm{t}_{2 \mathrm{~g}}{ }^{6}$ set) are too tightly bound for chemical electron-oxidation, but if so the possibility of electrochemical generation of $\mathrm{AuF}_{6}$ still remains available. Higher oxidation states than $\mathrm{Au}(\mathrm{VI})$ appear to be beyond access. 


\section{CONCLUSIONS}

In comparison with silver, the greater resistance of gold to oxidation, and the greater range of its oxidative chemistry, have been related to a relativistic effect. This causes the gold $\boldsymbol{s}$ electrons to be more bound, and the d electrons to be less bound, than their counterparts in silver. Although, for the closely bound set of $\mathrm{F}$ ligands (in square array) in $\mathrm{A}$ (III) fluorospecies $(\mathrm{A}=\mathrm{Au}, \mathrm{Ag})$ the $\mathrm{Au}$ (III) has nearly the same effective size as $\mathrm{Ag}$ (III), this is not the case for the non-bonding valence $\mathbf{d}$ orbital electrons. The $\mathrm{Au}(\mathrm{III}) \mathbf{d}$ electron-pair, normal to the $\left[\mathrm{AuF}_{4}\right]$ short-bonded set in $\mathrm{AuF}_{3}$, gives the $\mathrm{Au}(\mathrm{III})$ $\sim 0.22 \AA$ greater effective radius than its silver relative, in that direction. This correlates with the weaker binding of the $\mathrm{Au} \mathbf{5 d}$ electrons and with the facile addition of two $\mathrm{F}$ atoms to $\mathrm{AuF}_{4}^{-}$to yield $\mathrm{AuF}_{6}^{-}$.

\section{ACKNOWLEDGEMENTS}

The fluorine chemistry of gold and silver in anhydrous hydrogen fluoride was carried out with co-workers G. M. Lucier, S.H. Elder, and J.M. Whalen with the support of the Director, Office of Energy Research, Office of Basic Energy Sciences, Chemical Science Division of the U.S. Department of Energy under Contract Number DE-AC-03-76SF00098.

\section{ABOUT THE AUTHOR}

The author is an emeritus professor of chemistry and a principal investigator in the Division of Chemical Sciences, Lawrence Berkeley National Laboratory. His research interests have largely been concerned with the highest attainable oxidation states of the noble metals, and noble-gas chemistry.

\section{REFERENCES}

1 K. Pitzer, Accnts. Chem. Res., 1979, 12, 271

2 P. Pyykkö and J-P. Desclaux, Accnts. Chem. Res., 1979, 12, 276

3 N. Kaltsoyannis, J. Chem. Soc., Dalton Trans., 1997, 1

4 P. Pyykkö, Chem. Rev., 1988, 88, 563
5 A. Bayler, A. Schier, G.A. Bowmaker, and H. Schmidbaur, J. Am. Chem. Soc., 1996, 118, 7006; and U.M. Tripathi, A. Bauer, and H. Schmidbaur, J. Chem. Soc., Dalton Trans., 1997, 2865

6 W.E. Spicer, A.H. Sommer, and J.G. White, Phys.Rev., 1959, 115, 57

7 C.E. Moore, 'Atomic Energy Levels', Natl. Bur. Stand. (U.S.) Circ. 467, U.S. Govt. Print. Off. Washington, D.C., 1958

8 H. Hotop, R.A. Bennet, and W.C. Lineberger, J. Chem. Phys., 1973, 58, 2373; H. Hotop, and W.C. Lineberger, ibid., 1973, 58, 2379

9 L. Brewer, Lawrence Berkeley Laboratory Report LBL 3720 Rev. May 4, 1977

10 H.E. Swanson, and E. Tatge, 'Standard X-ray Diffraction Powder Patterns', Natl. Bur. Stand. (U.S.) Circ. 539, U.S. Govt. Print. Off. Washington, D.C., 1953, Vol I pp.23 and 33

11 N.E. Christensen, and B.O. Seraphin, Phys. Rev. B, 1971, 4, 3321

12 W.S. Rapson, Gold Bull., 1996, 29, 143

13 G. Lucier, S.H. Elder, L. Chacón and N. Bartlett, Eur. J. Sol. St. Inorg. Chem., 1996, 33, 809

14 G.M. Lucier, J.M. Whalen, and N. Bartlett, J. Fluo. Chem., 1998, 89, 101

15 G.M. Lucier, and N.Bartlett, to be published

16 B. Zemva, K. Lutar, A. Jesih, W.J. Casteel, Jr., A.P. Wilkinson, D.E. Cox, R.B. Von Dreele, H. Borrmann, and N. Bartlett, J. Am. Chem. Soc., 1991, 113, 4192

17 K. Lutar, S. Milicev, B. Zemva, B.G. Müller, B. Bachmann, and R. Hoppe, Eur. J. Sol. St. Inorg. Chem., 1991, 28, 1335

18 U. Engelmann, and B.G. Müller, Z. anorg. allg. Chem., 1991, 598/599, 103

19 S.H. Elder, G.M. Lucier, F.J. Hollander, and N. Bartlett, J. Am. Chem. Soc., 1997, 119, 1020

20 K. Lutar, A. Jesih, I. Leban, B. Zemva, and N. Bartlett, Inorg. Chem., 1989, 28, 3467

21 N. Bartlett, Angew. Chem. Int. Ed., 1968, 7, 433

22 N. Bartlett and K. Leary, Rev. Chimie Minérale, 1976, 13, 82

23 E. Miyoshi and Y. Sakai, J. Chem. Phys., 1988, 89, 7363

24 G. Lucier, C. Shen, W.J. Casteel, Jr., L. Chacón, and N. Bartlett, J. Fluor. Chem., 1995, 72, 15 